\title{
The Study on the Significance and Strategies of Career Planning in the Cultivation of Higher Vocational College Students
}

\author{
Wenbo Zhang \\ Liaoning Mechatronics College, Dandong Liaoning Province, China \\ arnold0110@sina.com
}

\begin{abstract}
Keywords: Career planning; Higher vocational college students; Education mode; Professional ability training; Resolution strategy
\end{abstract}

\begin{abstract}
The social employment environment makes the employment of the higher vocational college students facing a lot of pressure and difficulties, and the knowledge structure and ability accomplishment of the higher vocational graduates have gap with the employer's requirements. On the one hand, it is difficult for employment unit to find a suitable candidate, on the other hand, which also makes many graduates cannot find a satisfactory job, all of the above lead to a huge employment pressure eventually. In this case, the career planning in the cultivation of higher vocational college students will has more practical significance. From the present situation and significance of career planning, this paper analyzes the current higher vocational students' career planning, and expounds the problems of career planning for higher vocational college students. Then, the considerations and exploratory studies on the career planning and solution strategies are made in the cultivation of higher vocational college students.
\end{abstract}

\section{Introduction}

As a group of receiving higher education, higher vocational education has both the commonness of higher education, also has its own uniqueness. Relative to the undergraduate and graduate students, college students have relatively outstanding skills. In the meantime, they are facing the weakness of weak theoretic culture. In addition, under the effect of a variety of social factors, such as training system and the social environment and the higher vocational colleges graduates own reasons, a lot of threats and pressure are faced on their employment. Therefore, higher vocational students' employment is not just an individual problem, but also a social problem. To solve the problem of higher vocational college students' employment also must rely on the interaction of individuals, families and society and the whole social system's coordination and cooperation $[1,2,3]$. In this background, correct and effective career planning has positive meaning and important impact to solve the problem of higher vocational students' employment. Aim at the basic present situation and the existing problems in the education of current higher vocational education personnel training, this article go ahead an analysis and consideration on higher vocational students' career planning, and put forward the solving strategy of vocational career planning in the cultivation of higher vocational college students. The article mainly includes:

1) Studied the concept, research status and significance of career planning.

2) Analyzed the problems in terms of the career planning of higher vocational college students.

3) Put forward the solution strategy of higher vocational college students' career planning.

4) Summary.

\section{The Concept, Development Status and Significance of Career Planning}

A career is one person's professional experience,it refers to all the behaviors and activities associated with occupation in a person's life, and the process of consecutive experiences that related attitudes, values, aspiration and so on, it is also the process of position and work change and the realization of 
their ideal ,that is to say career is a dynamic process, it is not included in which professional is successful or not, each working people has their own career.

Career planning refers to the combination of individuals and organizations, making analysis and weigh on their own Interest, hobby, ability, specialty, experience and inadequate based on the study of the determination, analysis, summary on the subjective and objective conditions of a person's career,integrating era peculiarities at the same time,according to their own career tendency,determining the best career goals for he, and make effective arrangements to achieve this goal in the end.

As early as the 1950s,Japan's employment choice guidance has been extended from the original simple "career guidance" to ways of living.Many western developed countries carry on the education of career planning thoughts in the early period of the students, teaching students plan their career life at an early age.The most widely accepted is the career planning education mode of the United States, Career planning has been generally accepted and obtained a unprecedented development in America during the 1960 to 1970 ,"Career planning education" courses began to popularize in schools at all levels.After 1980,the career planning theory has in a state of accelerated development all the time,specific performance is:theory become more professional and comprehensive ;applications become more universal and specific on;policy become more standardization and regularization.At present, the career planning theory research abroad has entered the mature stage,such as Holland's vocational interest theory,Ginsburg and super's Career Development Theory,Bloom's theory of education goal,Rick's mental model theory and so on.It is not only its theoretical research is perfect, but also the development of practical system for career planning is relatively perfect.According to each person's personality, a lot of company to carry out career planning design services, strive for everyone to find the most suitable job,to maximize the use of the talent resources. At the same time, colleges and universities keep close touch with some companies, by organizing internships and work for students, enhance the students' social practice ability and social adaptability, to provide the opportunity to choose each other for both the supply and the demand.And thus formed the scientific methods of career planning which combine theory and practice [4,5].

The origin of career planning education is early in our country,At the end of the 19th century, career planning education has entered the education field of our country,learning plenty of advanced ideas and things from foreign has become the main content of vocational education. And get the support and encouragement of many famous schools and scholars,as early as 1916, Tsinghua university has carried out many career planning education activities, and set up relevant institutions.But, the development of the career planning lack of corresponding social conditions and the soil that can support its sprouting, career planning theory failed to spread across the country in the end.

The early stage of the stagnation in the development of the career planning is the period between the founding of new China and reform and opening up.In this period, career planning has not receive enough attention because of the distribution system of planned economy, the development of the career planning nearly at a standstill.

Today is the new period for the development of the career planning. At present, China's career planning education has been widely carried out throughout the country,teachers and personnel engaged in related works are aware of the necessity that use the advanced concept of career planning serve students,many higher vocational colleges carried out the employment guidance activities and employment survey,career planning education exist as an independent branch of education. Many domestic scholars have also devoted to the research and practical investigation of the career planning education theory [6].

However, career planning education in our country is still at an initial development stage,In terms of theory research career planning education is still in groping and perfect stage, The research of many theories is not enough in-depth.We have not pay enough emphasis on college students' career planning, It is not optimistic to the situation of specific implementation [7]. At the same time, there is a big gap between various universities in our country and abroad on carrying the career planning 
work.And employment guidance system is not perfect,the level of professional teachers is uneven.Therefore, career planning in our country still needs to be developed and improved constantly.

\section{The Problems of Higher Vocational College Students on Career Planning}

Higher Vocational Students' Weak Consciousness on Career Planning. As internal cause,vocational students' own factors is the most important impact to the career planning, and there are serious shortage about the vocational students' Knowledge and action at the present time which lead to career planning is neglected in terms of their consciousness and it is difficult to achieve the expected effect in their action.A lot of higher vocational students think that career planning is an unrealistic thing,they never carry on detailed analysis for their own ideals, interests, personality, ability and so on, therefore their professional choice has a great deal of randomness.Some students know something about career planning,but they mistakenly think that making career planning while at school is still early, they will do well naturally after entering society. So with a weak consciousness, lack of power, in consequence, they are short of initiative to make career planning, even they have made the career planning, it will also not play a good role in the actual job search process on account of lack enough scientific and competitive.

The Misconceptions in Understanding of the Idea of Career Planning and Lack of a Clear Self Awareness. Part of the higher vocational students pursuit of "best choice" by the one-sided , want to take shortcuts in career planning to maximize the interests of individual infinitely, follow suit blindly, with utilitarian tendency, while they are not to do it down to a practical according to the needs of our society, industry needs and their own conditions.

In addition, many higher vocational college students conduct a comprehensive analysis to, knowing their strengths and weaknesses, as well as how their advantages and disadvantages matching with the environment, so as to foster strengths and circumvent weaknesses, it is an important content of career planning. But in real life, due to the lack of clear cognition of themselves, and a high self-assessment, all above lead to career planning can't run smoothly and achieve expected effect.

Inadequate Preparation for Career Planning. Career planning is not a static behavior, but a dynamic process of combine their personal internal factors such as vocational interest, traits of character and advantages of specialty with external factors, so as to establish their own career and realize the life value. In this process, it is a link cannot be ignored that preparing for the career planning, many students still stay in the status of learning of cultural knowledge 'mechanical', but ignore the important effect of career planning in the development of employment in the future, Inadequate preparation for career planning, all of these make them unquestioning on the job choice in the future $[8,9,10]$.

\section{Career Planning Strategy of Higher Vocational Students}

There is an important meaning of career planning in the higher vocational students, and it is extremely urgent, but there are also many problems of higher vocational students' career planning, it is affected by various factors, if these factors do not get the proper solve, it is bound to affect the effect of students' career planning. How to face the future and provide a good career planning for higher vocational students, we need to build a interaction system of social, family, school and personal, make improvement in many aspects, from theory to practice, from awareness to tools, can we establish the pilot system of higher vocational students' career planning truly. This article put forward the strategies of higher vocational college students' career planning from the following aspects:

At the Government and the Social Level: to Strengthen the Supervision and Guidance. The guidance for higher vocational colleges and students' career planning from the government become an important duty, and also become an important means to guide the higher vocational education development. Only the governments bring vocational career and vocational students into the whole 
economic and social operation system, can the higher vocational career driven to the society and the social support for higher vocational career be really play.

Vocational education is the foundation engineering to improve the quality of workers and the competitiveness of national industrial, it is the urgent needs to build an innovation-oriented country and the socialist harmonious society that developing vocational education vigorously. In order to make students to carry on career planning actively, relieve employment pressure, we need the government to use indirect means to do some macroeconomic regulation and control with each college's career planning work. Government support and encourage the higher vocational colleges to carry on the career planning activities and employment guidance work by issued some encouraging measures. The government needs to establish a facilitating agency to offer services for career planning guidance, conduct a systematic management and supervision of the higher vocational colleges, to monitor and guidance each link of the career planning. In order to ensure the smooth implementation and conduct of the career planning education, the government should checks and visit the school students unscheduled. Through hold the career planning contests, encouraging students to implement the related activities, providing students with free career planning guidance and help them make career self-career planning .In addition, the government and schools should provide students with an opportunity of practice and internship, helping students to do enough practice.

School Level: Enhance Awareness, Improve Ability. Higher vocational colleges is the main body in which the higher vocational talents training and cultivation implement, it is also the object that vocational students feel directly, so the quality of higher vocational colleges directly determines the effect of students' career planning, to guide and management college students' career planning need higher vocational colleges take actions from the following two aspects mainly:

Establish and Improve the Level of Professional Teaching Staff for Career Planning Education. In order to guide students make career planning correctly, professional teachers is the key to guarantee the quality of teaching. This needs to encourage their teachers to further study, improving their teaching level and quality, building a group of teachers which are professional, experienced and positive ultimately. On the other hand, higher vocational colleges should provide students with the scientific and high quality career counseling by employing the experts from enterprises and institutions to guide students' career planning.

Perfect the Evaluation System of Career Planning. Professional evaluation can not only help students discover their professional interest, professional ability and professional orientation effectively, but help students to test and analysis their professional quality such as communication ability, organization and coordination ability, team cooperation ability, logical thinking ability, then we can support proposal for their career planning on this basis, helping students form a scientific and reasonable career planning report. This needs higher vocational colleges formulate a set of perfect assessment system of career planning in the process of cultivating students, so as to make the guidance of student's career planning more effectively.

The Student Level: Change the Idea, Put It Into Action. Higher vocational students determine the process and effect of career planning directly as the direct benefit object of career planning. This requires higher vocational college students to realize the importance of career planning fully, strengthen their consciousness of self-career planning, develop workable plan and revised and adjust their planning objectives constantly. Career planning should be throughout the learning phase of college students, participate in and learning from counseling and lectures of career planning actively, collect knowledge from career planning seriously, understand yourself fully, planning your career as early as possible, make effort and struggle with a goal and direction during the whole university, find the guidance and motivation to go forward, planning a better career blueprint for yourself.

In addition, the higher vocational college students' career planning should be formulated in line with their actual situation, and put both the possibility and the feasibility of the implementation of career planning into consideration. And keep an eye on the social demand for talents and carry on some reasonable adjustment on the planning objectives timely, so as to adapt to the fast pace of modern society duly, to ensure realize the career planning. 


\section{Conclusion}

In view of the current importance of career planning in the cultivation of college students, this article made further study of the concept, research status and significance of career planning, analyzed the problems of higher vocational college students' career planning, discussed the necessity of students' career planning from three aspects include government, school and individual, and put forward the solving strategy of higher vocational college students' career planning.

\section{References}

[1] Ye Jianming, Liang Ningsen, Study on dynamic mechanism of integration of schools and enterprises of higher vocational education $[\mathrm{J}]$. Vocational \& Technical Education Forum. 2014(08):P16-P22, 26.

[2] Wang xiang, Vocational education “project-specific" teaching model building path and practice effect study [J]. China Adult Education. 2014(11):P119-P122.

[3] Shi Lihong, Zhu Dewen, Construction of Vocational Education Project-specific Course Situated Teaching Organization [J]. Vocational \& Technical Education Forum. 2011(06):P59-P62.

[4] S. R. Hu, H. Zhao. Practice and Exploration of the Certification of Engineering Education in Electronic Information Engineering Specialty [J]. Journal of Wuhan University, 2012, 2:130-132. Nicole, “Title of paper with only first word capitalized," J. Name Stand. Abbrev, in press.

[5] Shen Guoliang, Exploration of existing problems in project teaching course development [J]. China Adult Education. 2010(11):159-160

[6] Wang wei, Exploration of “project-oriented" course development in interior design major of higher vocational colleges [J]. Education and Vocation. 2010(15): P108-P109.

[7] Yao Wanqiang, Li Chonggui, Ma Qingxun, Qiu Chunxia, Hu Rongming. Research on the teaching and educational reform of geographic information system [J]. Technology and Innovation Management, 2011, 32(2): 2011, 32(2):195-198.

[8] Han Chaoying. Analysis on the Epochal Character of the Work of College Head-teacher [J]. Jilin Provincial Institute of Education. 2009, 25 (II):73-74.

[9] X. Z. Zhe, A. W. Han. The Present Situation, problems, and countermeasures of Higher Engineering Education in China [J]. Shanghai Journal of Educational Evaluation, 2015, (04):21-26.

[10] Dong Jiandang, Sun Zhuohui. To maintain the role of instructors in security and stability of college [J]. Science \& Technology Information.2010 (I): 52-53. 